\title{
Study of cyclone effect in Kamchatka on electron distribution in the ionosphere by satellite tomography in the conditions of low seismicity
}

\author{
Vadim Bogdanov* \\ Institute of Cosmophysical Research and Radio Wave Propagation FEB RAS, Paratunka, Russia
}

\begin{abstract}
The paper presents the results of investigation of cyclone possible effect on ionosphere parameters. Monitoring of ionosphere state has been carried out by automatic sounding applying low orbital navigational spacecrafts in the conditions of low seismicity. Receiving stations were locating in meridian direction of Kamchatka peninsula in Paratunka, Mil'kovo and Esso villages. It has been shown that during nighttime cyclone passage (according to local time) on 18.01., 03.02. and 17.02.2013 over Kamchatka, synchronous increase of electron concentration occurred in the region over its epicenter in comparison to the next days without cyclones. With the increase of the latitude, i.e. further from the center of the cyclone, electron concentration decreased in comparison to calm days.
\end{abstract}

\section{Introduction}

The geographical location of the Kamchatka region has a number of features. Kamchatka, being in the area of transition from the Asian continent to the Pacific ocean, is the most seismic region of Russia. The whole territory of the region is located in the area of 5-9 point earthquake zone (on a 12-point scale). The known fact is the relationship of the ionosphere with the processes in the earth's lithosphere. However, it is difficult to register a reliable prognostic sign of a seismic event in the behavior of ionospheric parameters, since the earth's atmosphere is an open dynamic system. Consequently, variations in the ionospheric parameters cannot be fully explained without taking into account the influence of the underlying atmospheric layers. Consequently, physical processes formed in the lower and middle atmosphere can provoke changes in the parameters in the overlying layers [1]. It is possible that atmospheric phenomena such as cyclones can affect the state of the ionosphere. Works have already been done to investigate the links between wave disturbances in the atmosphere and weather conditions. Wave-like disturbances in the ionospheric parameters were observed during storms [2], and quasi-periodic oscillations were detected during severe thunderstorms [3]. At the moment, there are articles devoted to

\footnotetext{
* Corresponding author: vbogd@ikir.ru
} 
the study of the possible influence of tropical cyclones on different layers of the ionosphere. Disturbances of this kind were recorded in various ways. The Doppler frequency shift measurements revealed the presence of medium-scale moving ionospheric disturbances (MID) in the ionosphere during storms with a period of about $20 \mathrm{~min}$. [4]. Using vertical and inclined ionosondes it was shown that at a distance of about $3 \div 5$ thousand $\mathrm{km}$ from the center of the cyclone there was a change in the parameter $f_{0} F 2$ by $10-20 \%[5,6$.$] . The$ authors believe that the increase in [7] or decreases [8] the critical frequency $f_{0} F 2$ may be related to the delay of the measurement moment with respect to the cyclone nucleation time. In the works $[9,10]$ were found time intervals of amplification of the signal spectrum power at certain frequencies. With the help of GPS measurements [11] it was found an increase in the activity of acoustic-gravitational waves by $20-30 \%$ at the stage of rapid changes in the power of the hurricane. However, there are studies in which the relationship between cyclones and changes in ionospheric parameters has not been identified [12].

As sources of coherent signal uses low-orbit navigation satellites. This work continues the cycle of researches on search of influence of tropospheric disturbances (winter and spring cyclones) on the behavior of ionospheric parameters for a better understanding of tropospheric-ionospheric interaction. To perform these studies, the data obtained by tomographic sensing using receiving stations located in the meridional direction on the Kamchatka peninsula were used. A distinctive feature of the proposed article from the cited works is the location of receiving stations of tomographic sensing in the area of action of cyclones. This gives the opportunity to obtain the meridional distribution of electrons in the regions of the ionosphere located over the area of the cyclone operation.

\section{Description of the method}

Radiotomography sounding of the ionosphere performed over the territory of the Peninsula of Kamchatka with the help of ray radiotomography. The problems of ray radiotomography are solved in practice with the help of satellites and several receivers. Several stations receiving the navigation signal are located on the Earth's surface at an angle corresponding to the angle of inclination of the satellite orbit plane. In the case of systems of type "Cicada/Transit", the inclination of the orbit which is $83^{\circ} / 90^{\circ}$ degrees, it is necessary to have ground-based receivers of navigation signals in the meridional direction.

On the ground, the reduced phases of signals with frequencies of 150 and $400 \mathrm{MHz}$ can be used to calculate the electronic content in the path of the navigation signal. During the passage of the satellite over the deployed system of ground stations, a series of measurements is carried out, for each station receiving the navigation signal, and is determined

$$
T E C=\int_{p} N_{e} d s
$$

(where TEC is the complete electronic content along the path of the signal propagation between the source and receiver $p, N e$ is the electronic content), on the element of the ds propagation path, then the reconstruction of the tomographic section of the ionosphere is carried out by solving the inverse problem $[13,14]$. On the Fig. 1 the scheme of realization of the method of tomographic sounding of the ionosphere allowing to restore electronic concentration in the upper atmosphere is presented. This allows to restore the vertical distribution of the electron concentration along the satellite flight path with a good resolution $(25 \mathrm{~km}$ in height and $50 \mathrm{~km}$ in latitude). Ground receivers are located in the villages Paratunka (Par), Milkovo (Ml), Esso (Ess) in the submeridional direction (158 $31^{\prime}$ E). Receiving stations operate in automatic mode. 


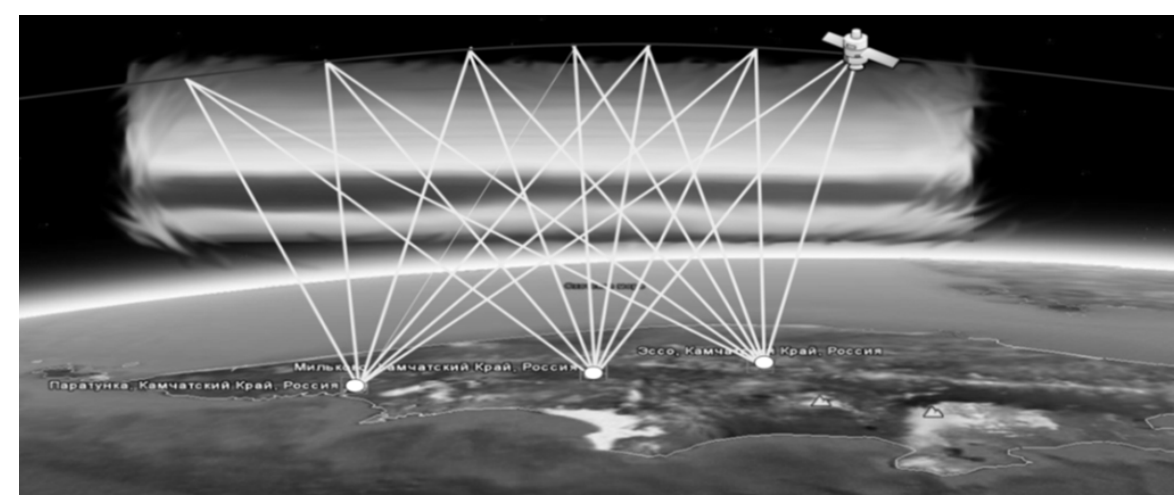

Fig. 1. The scheme of location of stations of reception and distribution of the probing signal.

\section{Analysis of experimental results}

To study the ionospheric response, cyclones passed over Kamchatka in the period from January to February 2013 (see Table 1) in a calm and moderately quiet magnetic environment $(\mathrm{K} \leq 17)$ were selected. During their passage in the Kamchatka region there were no strong earthquakes. This makes it possible to hope that if there are effects of cyclones on the ionosphere, this effect will not be masked by processes occurring in the earth's lithosphere. The left half of Table 1 shows the date of passage of the cyclone, the time of flight of the satellite (UT), the total on this date, the three-hour index of magnetic activity (Kp) on the magnetic station "Paratunka". The right half of the table shows the information of the day nearest to the cyclone (reference day), with respect to which the meridional distribution of electrons was determined for comparison. The time of satellite flight on the reference day was chosen as close as possible to the time of flight on the day of the cyclone.

Table 1. The day with and without the cyclone.

\begin{tabular}{|c|c|c|c|c|c|}
\hline \multicolumn{3}{|c|}{ The day with the cyclone } & \multicolumn{3}{c|}{ The day without the cyclone } \\
\hline Date & $\begin{array}{c}\text { The time of } \\
\text { flight of the } \\
\text { satellite, UT }\end{array}$ & $\begin{array}{c}\text { The total } \\
\text { Kp index }\end{array}$ & Date & $\begin{array}{c}\text { The time of } \\
\text { flight of the } \\
\text { satellite, UT }\end{array}$ & $\begin{array}{c}\text { The total } \\
\text { Kp index }\end{array}$ \\
\hline 18.01 .2013 & $16: 00$ & 16 & 12.01 .2013 & $16: 20$ & 2 \\
\hline 03.02 .2013 & $18: 09$ & 7 & 31.01 .2013 & $18: 32$ & 1 \\
\hline 17.02 .2013 & $12: 33$ & 17 & 12.02 .2013 & $13: 07$ & 9 \\
\hline
\end{tabular}

For each cyclone, Figures 2, 4 and 6 present synoptic maps and tomograms of the submeridional electron height distribution for the day with and without the cyclone. On the tomograms in the $\mathrm{x}$-axis is latitude in degrees and designated receiving stations of satellite information Par, Ml, Ess, on the vertical axis is height in $\mathrm{km}$. To the right of the tomogram is shown the color scale of the distribution of the electron concentration. Tomograms are taken at the interval of latitude $48.01^{\circ} \mathrm{N}-61.52^{\circ} \mathrm{N}$. In Tables $1-4$ shows the maximum values of the electron concentration for three selected latitude $48.01^{\circ} \mathrm{N}, 52.96^{\circ} \mathrm{N}$ and $61.52^{\circ} \mathrm{N}$ for the cyclone and the corresponding reference day. Figures 3, 5, and 7 graphically show the height distributions of electron concentrations for these latitudes. 


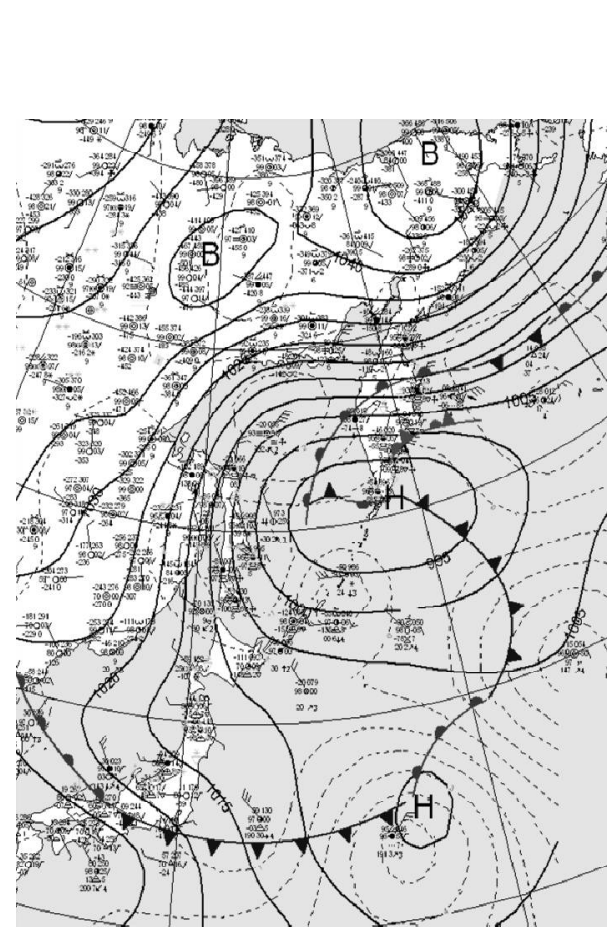

a)

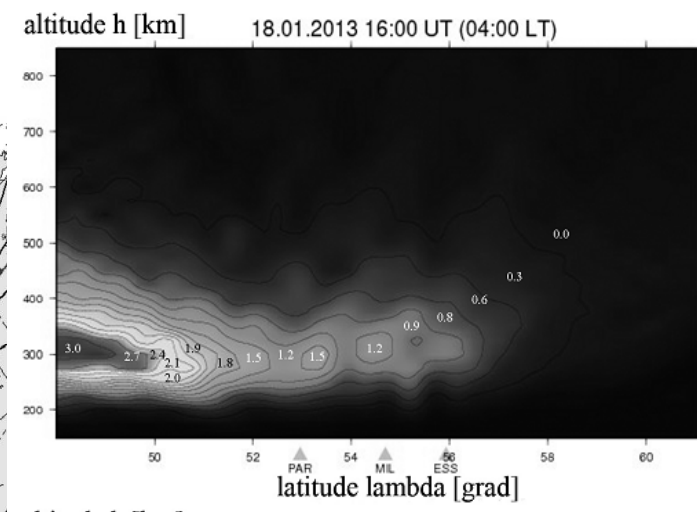

altitude $\mathrm{h}[\mathrm{km}] \quad$ 12.01.2013 16:20 UT (04:20 LT)

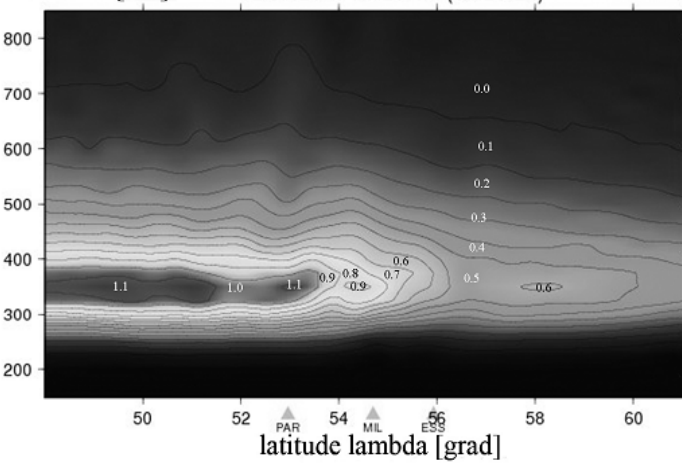

b)

Fig. 2. Cyclone 18.01.2013. a) At an altitude of $5 \mathrm{~km}$, the epicenter of the cyclone was located in the southern part of the Peninsula at $\sim 48^{\circ} \mathrm{N}$; b) 18.01.2013 16:00 UT observed by the turbulization of the ionospheric plasma with a strong plasma formation in the interval of latitudes $48^{\circ} \mathrm{N}-49^{\circ} \mathrm{N}$ and heights $290-350 \mathrm{~km}$ with increasing latitude.

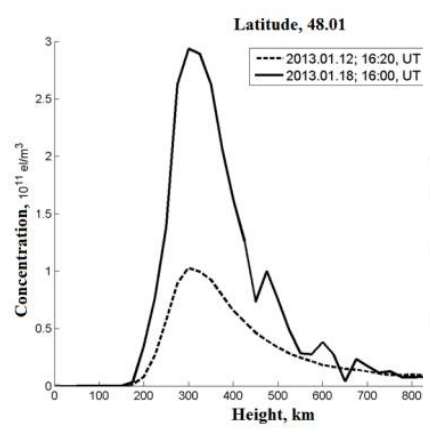

a)

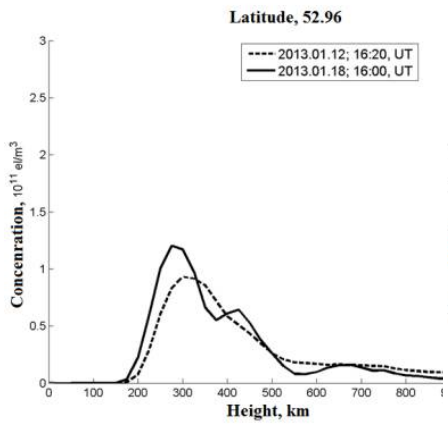

b)

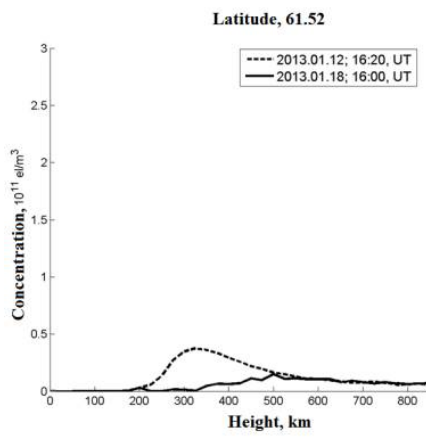

c)

Fig. 3. Section of the electron density distribution in the ionosphere for the cyclone for 18.01.2013 at 16: 00 UT (04:00 LT) (solid line) for three latitudes in comparison with the reference day 12.01.2013 (dotted line). 
Table 2. The maximum value of the electron concentration of the ionosphere, el $/ \mathrm{m}^{3}\left(\times 10^{11}\right)$

\begin{tabular}{|l|c|c|c|}
\hline \multirow{2}{*}{ The flight of the satellite } & \multicolumn{3}{|c|}{ Latitude } \\
\cline { 2 - 4 } & $\mathbf{4 8 . 0 1}^{\circ} \mathbf{N}$ & $\mathbf{5 2 . 9 6}^{\circ} \mathbf{N}$ & $\mathbf{6 1 . 5 2}^{\circ} \mathbf{~ N}$ \\
\hline $12.01 .2013 ; 16: 20$ UT & 1,0287 & 0,9313 & 1,0287 \\
\hline $18.01 .2013 ; 16: 00$ UT & 2,9366 & 1,2030 & 0,1486 \\
\hline $03.02 .2013 ; 18: 09$ UT & 1,2308 & 1,0143 & 0,1400 \\
\hline
\end{tabular}

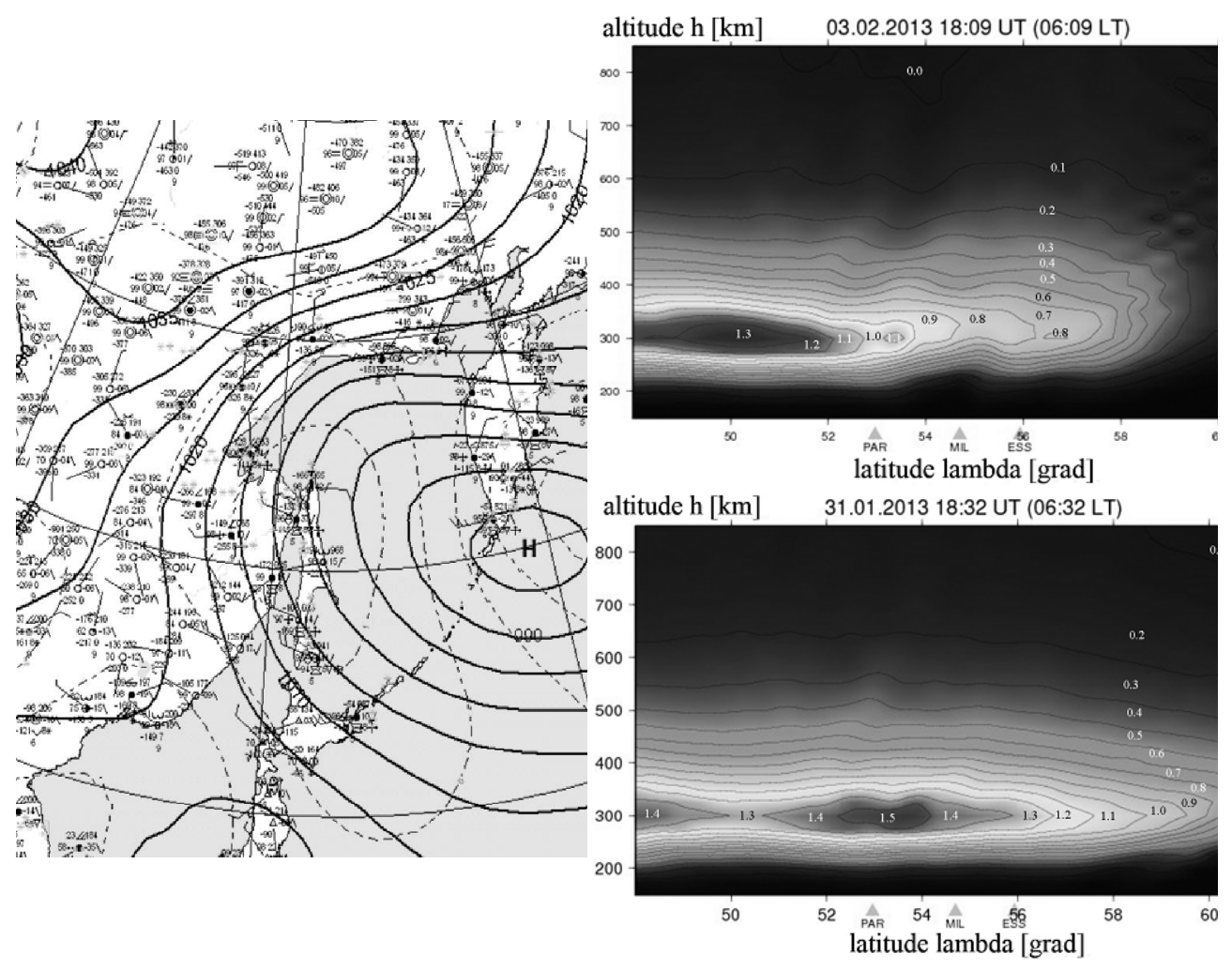

a)

b)

Fig. 4. Cyclone 03.02.2013. a) synoptic map corresponds to 15 UT. The wind of the South-Eastern direction reached $30 \mathrm{~m} / \mathrm{s}$ at an altitude of $5 \mathrm{~km}$. The epicenter of the cyclone was located in the southern part of the Peninsula at $\sim 48^{\circ} \mathrm{N}$; b) 03.02.2013 18:09 UT in the ionosphere observed by the turbulization of the plasma, and formed a long pronounced plasma formation with a high concentration of electrons in the interval of latitudes $49^{\circ}-52^{\circ} \mathrm{N}$ and heights $290-320 \mathrm{~km}$, compared to 31.01 .2013 .

Table 3. The maximum value of the electron concentration of the ionosphere, el $/ \mathrm{m}^{3}\left(\times 10^{11}\right)$

\begin{tabular}{|l|c|c|c|}
\hline \multirow{2}{*}{ The flight of the satellite } & \multicolumn{3}{|c|}{ Latitude } \\
\cline { 2 - 4 } & $\mathbf{4 8 . 0 1}^{\circ} \mathbf{N}$ & $\mathbf{5 2 . 9 6}^{\circ} \mathbf{N}$ & $\mathbf{6 1 . 5 2}^{\circ} \mathbf{~ N}$ \\
\hline $31.01 .2013 ; 18: 32$ UT & 1,3700 & 1,4290 & 0,4803 \\
\hline $03.02 .2013 ; 18: 09$ UT & 1,2308 & 1,0143 & 0,1400 \\
\hline
\end{tabular}




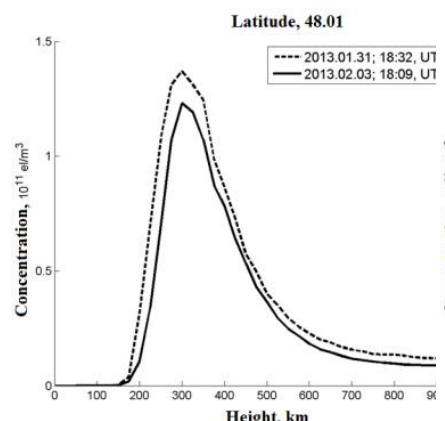

a)

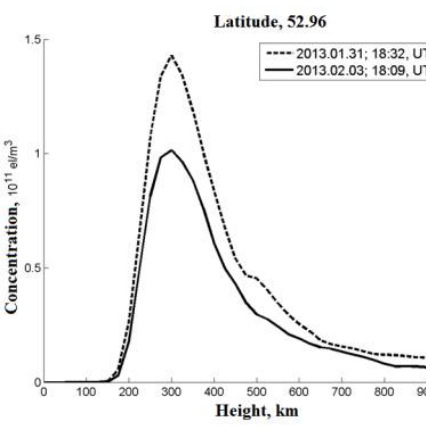

b)

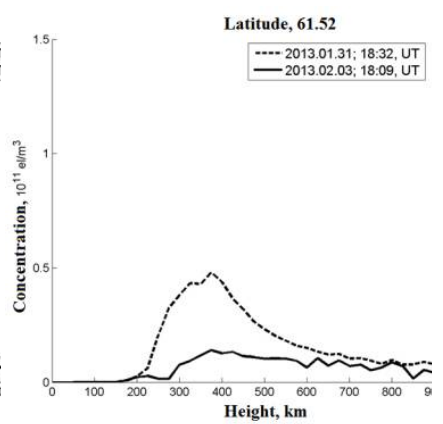

c)

Fig. 5. Section of the electron density distribution in the ionosphere for the cyclone for 03.02.2013 at 18: 09 UT (06:09 LT) (solid line) for three latitudes in comparison with the reference day 31.01.2013 (dotted line).

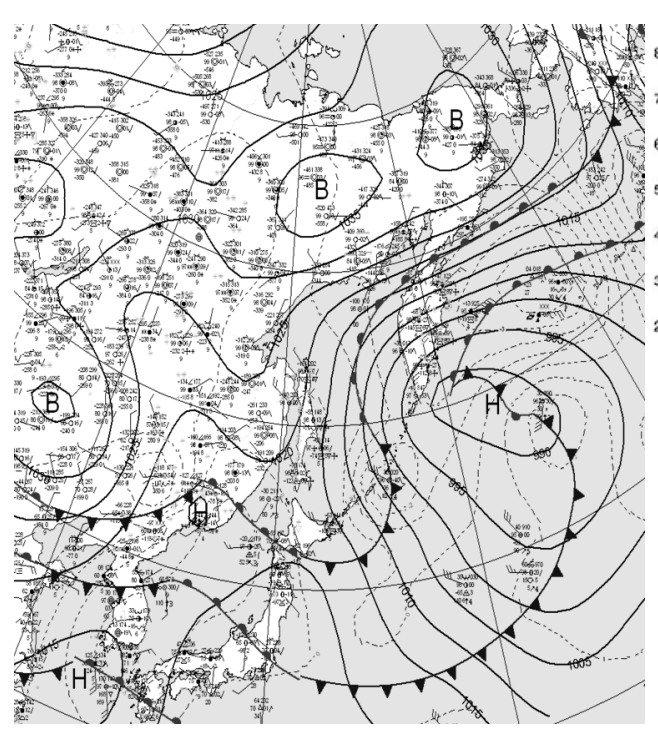

a)
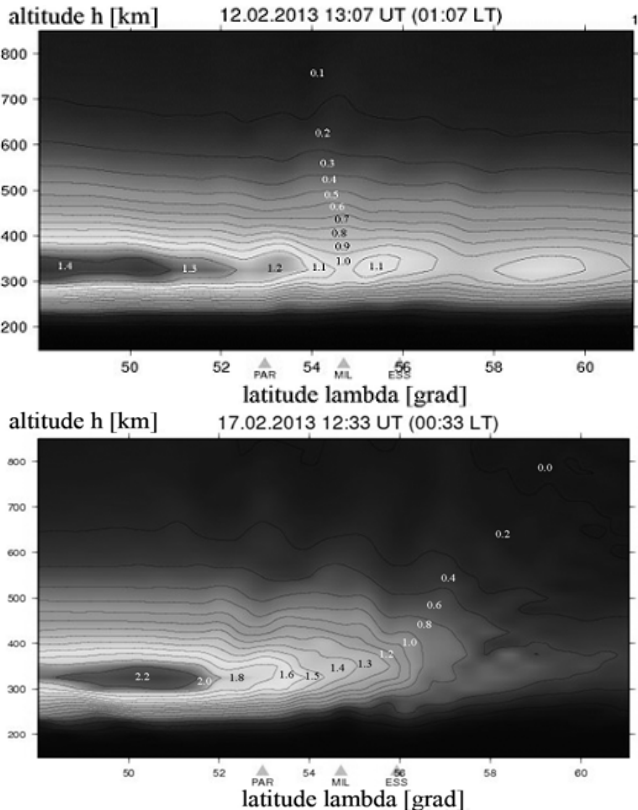

b)

Fig. 6. Cyclone 17.02 .2013 г. a) the synoptic map corresponds to 12 UT. Wind South-East, then East, reached $30 \mathrm{~m} / \mathrm{s}$ at an altitude of $5 \mathrm{~km}$. the epicenter of the cyclone was located in the Pacific ocean with coordinates: latitude $\sim 48^{\circ} \mathrm{N}$, longitude $\sim 162^{\circ} \mathrm{E}$; b) In the ionosphere 17.02.2013, at 12:33 UT there is turbulization of the plasma, and formed a long pronounced plasma formation in the interval of latitudes $49^{\circ}-52^{\circ} \mathrm{N}$ and heights of $280-320 \mathrm{~km} \mathrm{18.02.2013} \mathrm{09:20} \mathrm{UT} \mathrm{plasma} \mathrm{formation} \mathrm{stretched}$ $\left(48^{\circ}-53^{\circ} \mathrm{N}\right)$, with the formation of two regions of high electron density. On the second day of the cyclone, the area of increased concentration spread to higher latitudes (see Table 4).

Table 4. The maximum value of the electron concentration of the ionosphere, $\mathrm{el} / \mathrm{m}^{3}\left(\times 10^{11}\right)$.

\begin{tabular}{|l|c|c|c|}
\hline \multirow{2}{*}{ The flight of the satellite } & \multicolumn{3}{|c|}{ Latitude } \\
\cline { 2 - 4 } & $\mathbf{4 8 . 0 1}^{\circ} \mathbf{N}$ & $\mathbf{5 2 . 9 6}^{\circ} \mathbf{N}$ & $\mathbf{6 1 . 5 2}^{\circ} \mathbf{N}$ \\
\hline $12.02 .2013 ; 13: 07$ UT & 1,3930 & 1,2171 & 0,8099 \\
\hline $17.02 .2013 ; 12: 33$ UT & 1,9534 & 1,7840 & 0,4352 \\
\hline
\end{tabular}




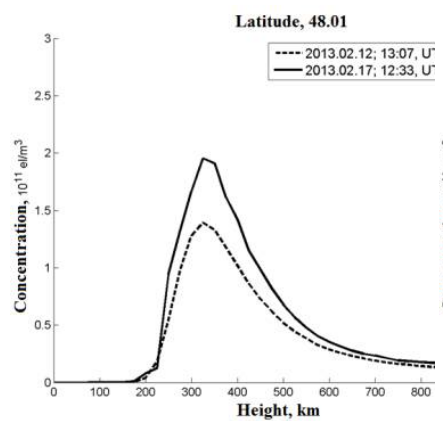

a)

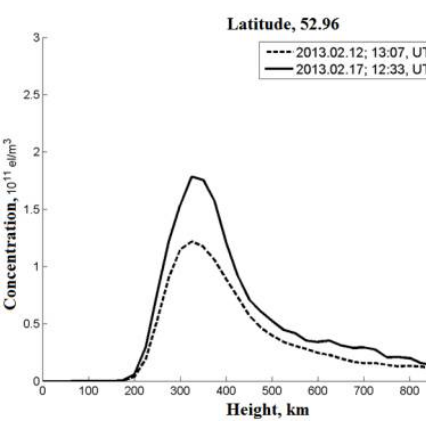

b)

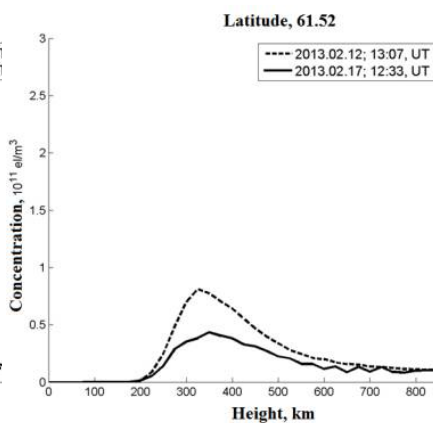

c)

Fig. 7. Section of the electron density distribution in the ionosphere for the cyclone for 17.02 .2013 at 12: 33 UT (00:33 LT) (solid line) for three latitudes in comparison with the reference day 12.02.2013 (dotted line).

\section{Summary}

The analysis of the development of cyclones showed that:

- For two of the three cyclones there is an excess of electron concentration compared to the reference days near the center of the cyclone. For the event of 03.02.2013, the electron concentration near the center of the cyclone was less by about $10 \%$. The authors believe that the increase [7] or decrease [8] of the concentration in foF2 may be due to the delay of the measurement moment relative to the time of cyclone nucleation.

- Maximum turbulence of the ionosphere occurs directly above the area of the center of the cyclone, which is characterized by sharp gradients in the distribution of electrons. The variation of the electron concentration of the ionosphere can be explained by the transfer of mechanical impulse to the lower layers of the ionosphere and neutral atmosphere [1] at the height of F-layer and the influence of the boiler, generated by the cyclone.

- It is necessary to conduct further studies of the impact of the cyclone on the ionosphere for a set of statistics and the construction of appropriate physical models, in order to clarify the mechanism of transmission of the momentum of the vortex motion of the cyclone to the ionospheric heights.

\section{References}

1. A. Danilov., E. Kazimirovskiy, G. Vergasova, G. Khachiyan, Meteorological effects in the ionosphere (Gidrometeoizdat, 1987)

2. Baker, Davis, J. Geophvs. Res, 70 (1965)

3. S. Prasad, L. Schneck K. Davies, J. Atmos. Terr. Phys., 37 (1975)

4. Z. Xiao, S. Xiao, Y. Hao, D. Zhang J. Geophys. Res., 112 (2007)

5. L. Vanina-Dart, A. Romanov, E. Sharkov, Geomagnetism and Aeronomy, 51, 3 (2011)

6. L. Vanina-Dart, E. Sharkov, Issledovanie Zemli iz kosmosa, 3 (2016)

7. D. Rice, J. Sojka, J. Eccles, R. Schunk, Radio Sci. 47 (2012)

8. Y.-M. Liu, J.-S. Wang, Y.-C. Suo, Adv. Geosci. 29 (2006)

9. Yu. Mikhailov, G. Mikhailova, O. Kapustina, G. Druzhin, N. Cherneva, Geomagnetism and Aeronomy, 45, 6 (2005)

10. M. Chernigovskaya, V. Kurkin, I. Orlov I. et al., Issledovanie Zemli iz kosmosa, 5 (2010) 
11. V.Zakharov, V. Kunitsyn, Geomagnetism and Aeronomy. 52, 4 (2012)

12. E. Afraimovich, S. Voeykov, A. Ishin, et al., Geomagnetism and Aeronomy, 48, 5 (2008)

13. E. Andreeva, V. Kunitsyn, E. Tereschenko, Geomagnetism and Aeronomy, 32, 1 (1992)

14. A. Romanov, A. Romanov, S. Trusov, Yu. Urlichich, Kosmonavtika i Raketostroenie, 1 (2006) 